\title{
Allelopathic activity of Acacia concinna pod extracts
}

\author{
Sutjaritpan Boonmee* and Hisashi Kato-Noguchi \\ Department of Applied Biological Science, Faculty of Agriculture, Kagawa University, Miki, Kagawa 761-0795, Japan
}

\section{A B S T R A C T}

\begin{abstract}
Acacia concinna (Willd.) DC. (Fabaceae) has been used as a traditional medicine and its pharmacological and toxicological properties are well-known. However, no study has reported on its allelopathic property. In this study, the pod of $A$. concinna was extracted with aqueous methanol to investigate for allelopathic activity and for the isolation of allelopathic substances. Result showed that A. concinna pod extracts inhibited the growth of shoots and roots of cress (Lepidium sativum L.), lettuce (Lactuca sativa L.), alfalfa (Medicago sativa L.), rapeseed (Brassica napus), barnyard grass (Echinochloa crus-gallis L.), Italian ryegrass (Lolium multiflorum Lam.), foxtail fescue (Vulpia myuros (L.) C. C. Gmel.) and timothy (Phleum pretense L.) at concentration of 3 and 1 mg dry weight equivalent extract $/ \mathrm{mL}$, respectively. The growth decrease as the concentration of the pod extracts increase. The $I_{50}$ values of test plant shoots and roots ranged between 1.00-5.17 and 0.02-2.59 mg dry weight equivalent extract $/ \mathrm{mL}$, respectively. The inhibition on the roots was stronger than the shoots of test plants. The pod extracts were purified by column chromatographies and the inhibitory substance ACP-1 was isolated which inhibited the shoots and roots of cress by 27.1 and $14.4 \%$ of control length, respectively. Results indicated that the pod of $A$. concinna has allelopathic activity and ACP-1 may cause this activity. The pods and pod extracts of $A$. concinna could, therefore, be utilized for weed management and control
\end{abstract}

Keywords: Acacia concinna; Allelopathic activity; Medicinal plant; Inhibitory effect; Alternative weed management

\section{INTRODUCTION}

Weed invasion is a serious problem in crop plantation leading to the reduction in quality of crop produce and quantity of crop yields. The use of synthesis herbicides is widely considered as a quick and effective way to control weeds. However, their application results in chemical residues in agricultural products, and environmental pollution and contamination (Aktar et al., 2009). Global concern regarding the negative impacts of synthesis herbicides is increasing (Gandhi and Snedeker, 1999). Therefore, researchers are attempting to find alternative ways to minimize these problems and sustain agriculture management based on natural compounds.

Allelopathy is a biological process by which plants release allelochemicals into the surrounding environment in several ways. Allelochemicals interfere with the growth of other organisms by disrupting various physiological processes and also affecting rates of water uptake and plant hormonal balances (Rice, 1984; Soltys et al., 2013; Cheng and Cheng, 2015). Medicinal plant species produce plenty of secondary metabolites which are responsible for the various pharmacological properties including antioxidant, antimicrobial, antipyretic, anticoagulant and anti-inflammatory activities (Dahanukar et al., 2000 and Chandra and Rawat, 2015) as well as allelopathic properties (Duke et al., 1987; Swain, 1997 and Fujii et al., 2003). Nasrine et al. (2011) discovered that aqueous extracts of two medicinal plants (Euphorbia guyoniana and Retama retam) inhibited the germination of two invasive weeds (Bromus tectorum and Melilotus indica) and a common wheat (Triticum aestivum). Rawat et al. (2016) also found that aqueous extracts of different plant parts extracted from four medicinal plants (Asperagus racemosus, Picrorbiza kurroa, Valeriana wallichii and Ocimum sanctum) affected development and significantly reduced the seed germination of the pulse and oilseed crops. These results also indicated that the inhibitory activity of the medicinal plants was due to the occurrence of allelochemicals.

Acacia concinna (Willd.) DC. (Fabaceae) is a climbing shrub and a well-known medicinal plant widely used in Southeast Asia. The leaves, bark and pods have been used as a herbal medicine for emetic, purgative and expectorant treatments (Gafur et al., 1997; Kukhetpitakwong et al., 2006; Raja and

\footnotetext{
*Corresponding author:

Sutjaritpan Boonmee, Department of Applied Biological Science, Faculty of Agriculture, Kagawa University, Miki, Kagawa 761-0795, Japan. E-mail: sutjaritpanbm@gmail.com
}

Received: 02 September 2016; Revised: 13 February 2017; Accepted: 16 February 2017; Published Online: 27 February 2017 
Sivaraj, 2012). In addition, antioxidant, anti-coagulant, anti-platelet, anti-thrombotic, antidermatophytic and immune adjuvant activities are some of the valuable pharmacological properties of the plant (Kapoor et al., 1969, Kukhetpitakwong et al., 2006; Todkar et al., 2010; Rao et al., 2014; Sharma et al., 2014). Nonetheless, no study has been conducted regarding the allelopathic properties of this plant species. Therefore, the allelopathic activity and the allelopathic substances of $A$. concinna pods were investigated.

\section{MATERIALS AND METHODS}

\section{Plants material}

A. concinna (Willd.) DC. pods were collected from an area of Chiang Rai Province, Thailand in September 2014. Tiny particles soil or other contaminants were removed from the mature pods by washing thoroughly with tap water. The mature pods were then dried in the shade and ground into powder. Dicotyledonous plants; cress (Lepidium sativum L.), lettuce (Lactuca sativa L.), alfalfa (Medicago sativa L.), and rapeseed (Brassica napus), and monocotyledonous plants; barnyard grass (Echinochloa crus-gallis L.), Italian ryegrass (Lolium multiflorum Lam.), foxtail fescue (Vulpia myuros (L.) C. C. Gmel.) and timothy (Pbleum pretense L.) were selected for the bioassay.

\section{Extraction}

Powder of pods $(100 \mathrm{~g})$ of $A$. concinna was extracted with $70 \%(\mathrm{v} / \mathrm{v})$ aqueous methanol $(500 \mathrm{~mL})$ and kept in a sealed container for $48 \mathrm{~h}$. The extract was filtered through a sheet of filter paper (No.2, Toyo Roshi Kaisha Ltd., Japan). The residue was extracted again with $500 \mathrm{~mL}$ of cold methanol for $24 \mathrm{~h}$ and filtrated. The two filtrates were mixed and the solvent was removed until dry by using a rotary evaporator with water bath at $40^{\circ} \mathrm{C}$.

\section{Bioassay}

The residue of the pod extracts was dissolved with cold methanol and an aliquot of pod extracts at final concentrations of 1, 3, 10, 30, 100 and $300 \mathrm{mg}$ dry weight equivalent extract $/ \mathrm{mL}$ was added to a sheet of filter paper (No.2) in a $28 \mathrm{~mm}$ Petri dish. The solvent on the filter paper was evaporated in a draft chamber. Subsequently, $0.6 \mathrm{~mL}$ of $0.05 \%(\mathrm{v} / \mathrm{v})$ aqueous solution of polyoxyethylene sorbitan monolaurate (Tween 20; Nacalai, Kyoto, Japan), a mild surfactant and has no toxicity was added to the filter paper. Ten seeds of cress, alfalfa, lettuce and rapeseed were placed on filter paper in the Petri dishes. Ten germinated seeds of barnyard grass, Italian ryegrass, foxtail fescue and timothy were placed on filter paper in the Petri dishes after incubation with distilled water in dark at $25^{\circ} \mathrm{C}$ for 60,72 , 48 and $120 \mathrm{~h}$, respectively. Control seeds or germinated seedlings were placed on a filter paper soaked with the aqueous solution of Tween 20 without the extract. After incubation for $48 \mathrm{~h}$ in the dark at $25^{\circ} \mathrm{C}$, the length of shoots and roots of all test plant seedlings was measured. The percentage length of seedlings was determined by reference to the length of control seedlings. The bioassay was conducted in two independent experiments with three replications (10 seedlings/replication) for each experiment $(\mathrm{n}=60)$. The concentrations required for $50 \%$ inhibition $\left(I_{50}\right.$ value) of the test plants were calculated from the regression equation of the concentration response curves.

Isolation and purification of an allelopathic substance The pod extracts of $A$. concinna pods were evaporated to produce an aqueous residue using a rotary evaporator with water bath at $40^{\circ} \mathrm{C}$ (Fig. 1). Subsequently, the aqueous residue was then adjusted to $\mathrm{pH} 7.0$ with $1 \mathrm{M}$ phosphate buffer and partitioned three times with an identical volume of ethyl acetate. The ethyl acetate fraction was dehydrated over anhydrous $\mathrm{Na}_{2} \mathrm{SO}_{4}$, filtrated and evaporated until dry. The residue was separated by a column of silica gel (60 g; silica gel 60, 70-230 mesh, Nacalai Tesque, Kyoto, Japan), eluted stepwise with increasing amounts of ethyl acetate in $n$-hexane ( $10 \%$ per step, $\mathrm{v} / \mathrm{v}, 150 \mathrm{~mL}$ per step) and methanol $(300 \mathrm{~mL})$. Cress bioassay was used to determine the inhibitory activity of all separated fractions with three replications (10 seedlings/replication). The growth inhibitory activity was found in the fraction eluted by $70 \%$ ethyl acetate in $n$-hexane. The active fraction was evaporated until dry and the residue was separated by a column of Sephadex LH-20 (100 g, GE Healthcare, Uppsala, Sweden), eluted with increasing amounts of methanol in water $(20 \%$ per step, $\mathrm{v} / \mathrm{v}$, $150 \mathrm{~mL})$ and methanol $(300 \mathrm{~mL})$. The most active fraction was eluted by $40 \%$ aqueous methanol and evaporated until dry. The residue was dissolved with $20 \%$ (v/v) aqueous methanol and loaded onto a reverse phase $\mathrm{C}_{18}$ cartridge $(1.2 \times 6.5 \mathrm{~cm} ; \mathrm{YMC}$, Kyoto, Japan). The cartridge was eluted with increasing amounts of methanol in water $(20 \%$ per step, $\mathrm{v} / \mathrm{v}, 30 \mathrm{~mL})$ and methanol $(60 \mathrm{~mL})$. The most active fraction was eluted by $40 \%$ aqueous methanol and evaporated until dry. Finally, the residue was purified by using reverse phase HPLC (4.6 mm $\times 250$ i.d., Inertsil ODS-3; GL Science, Tokyo, Japan) eluted at a flow rate of $0.8 \mathrm{~mL} / \mathrm{min}$ with $35 \%$ (v/v) aqueous methanol and detected at $220 \mathrm{~nm}$.

\section{Statistical analysis}

The bioassay experiment was conducted in a completely randomized design. Data processing were analyzed by ANOVA and subsequent post hoc analysis with Dunnett's test. Two-tailed Pearson Correlation test was used to analyze the correlation of coefficient (R) between the extract concentration and the growth of test plants. All statistical analyses were performed using SPSS version 16.0. The concentrations required for $50 \%$ inhibition of each test plants were analyzed by GraphPad Prism 5.04. 


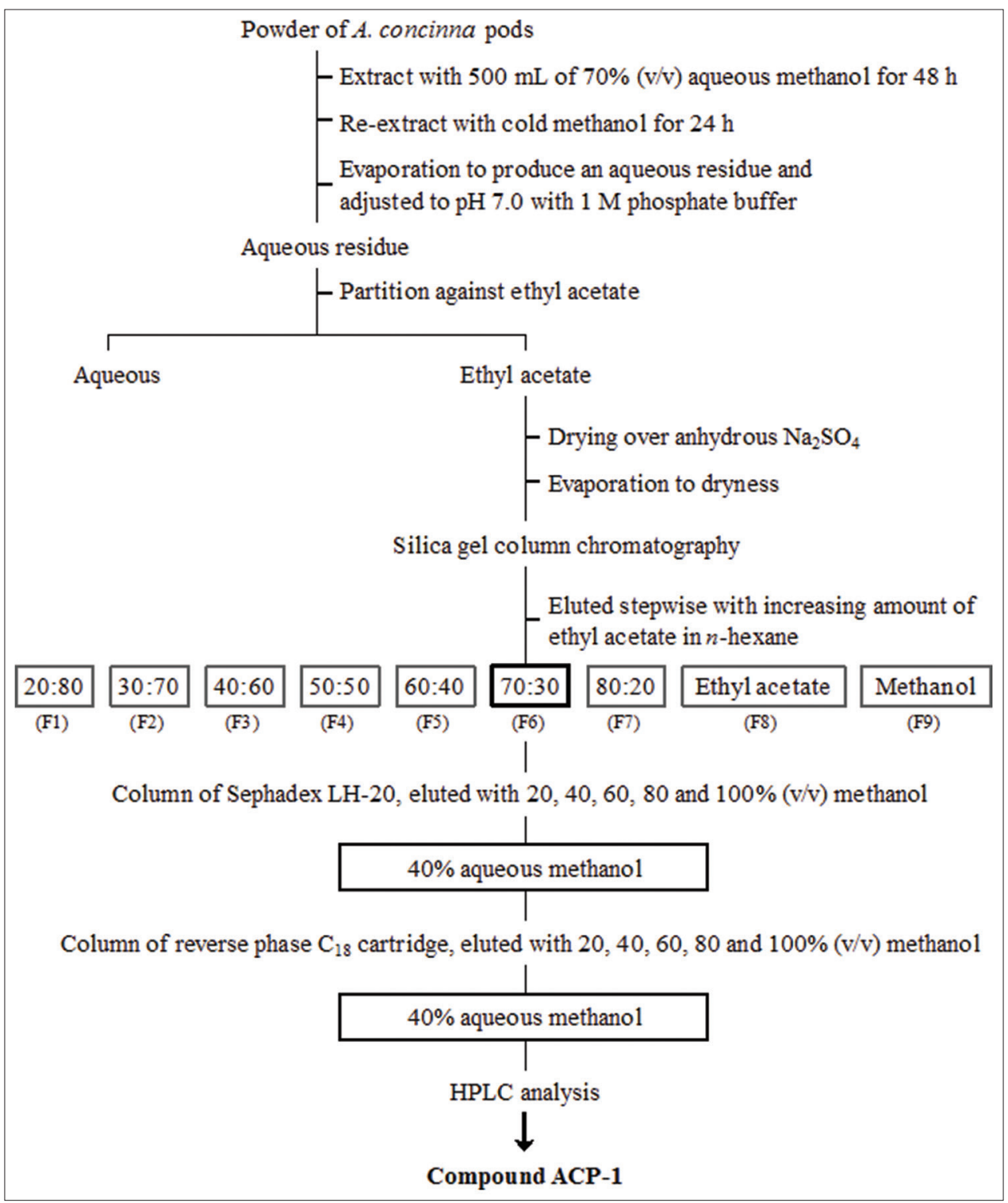

Fig 1. Procedure for extraction and isolation of substance ACP-1.

\section{RESULTS}

\section{Effects of pod extracts of $\boldsymbol{A}$. concinna on shoot length} of test plants

Shoot length of eight test plants was significantly inhibited by $A$. concinna pod extracts at concentrations $\geq 3 \mathrm{mg}$ dry weight equivalent extract $/ \mathrm{mL}(P<0.001)$ (Fig. 2). At $30 \mathrm{mg}$ dry weight equivalent extract $/ \mathrm{mL}$, shoots of lettuce and rapeseed seedlings were completely inhibited and Italian ryegrass, timothy, foxtail fescue, alfalfa, cress, and barnyard grass were significantly inhibited by $0.4,2.1,3.2,7.1,14.1$ and $25.6 \%$ of control length, respectively. The extract at $300 \mathrm{mg}$ dry weight equivalent extract $/ \mathrm{mL}$, shoots of cress and barnyard grass seedlings were significantly inhibited by 0.7 and $2.3 \%$ of control length and the other test plants were completely inhibited. Regression analysis between pod extract concentration and shoot length percentage showed negative correlation coefficient $(\mathrm{R})$ in all test plants (Table 1). The shoot length of barnyard grass and cress had a strong negative correlation with pod extracts and giving the correlation coefficients of -0.669 and -0.743 , respectively $(P<0.01)$. The $I_{50}$ value on the shoot length of all test plants ranged between 1.00 to $5.17 \mathrm{mg}$ dry weight equivalent extract/mL (Table 2). Shoot length of foxtail fescue was the most susceptible to the pod extracts, followed by lettuce, Italian ryegrass, timothy, rapeseed, alfalfa, cress, and barnyard grass.

\section{Effects of pod extracts of $A$. concinna on root length of test plants}

Root length of eight test plants was significantly inhibited by $A$. concinna pod extracts at concentrations $\geq 1 \mathrm{mg}$ dry weight equivalent extract $/ \mathrm{mL}(P<0.001)$ (Fig. 2). At $10 \mathrm{mg}$ dry weight equivalent extract $/ \mathrm{mL}$, roots of barnyard grass, 


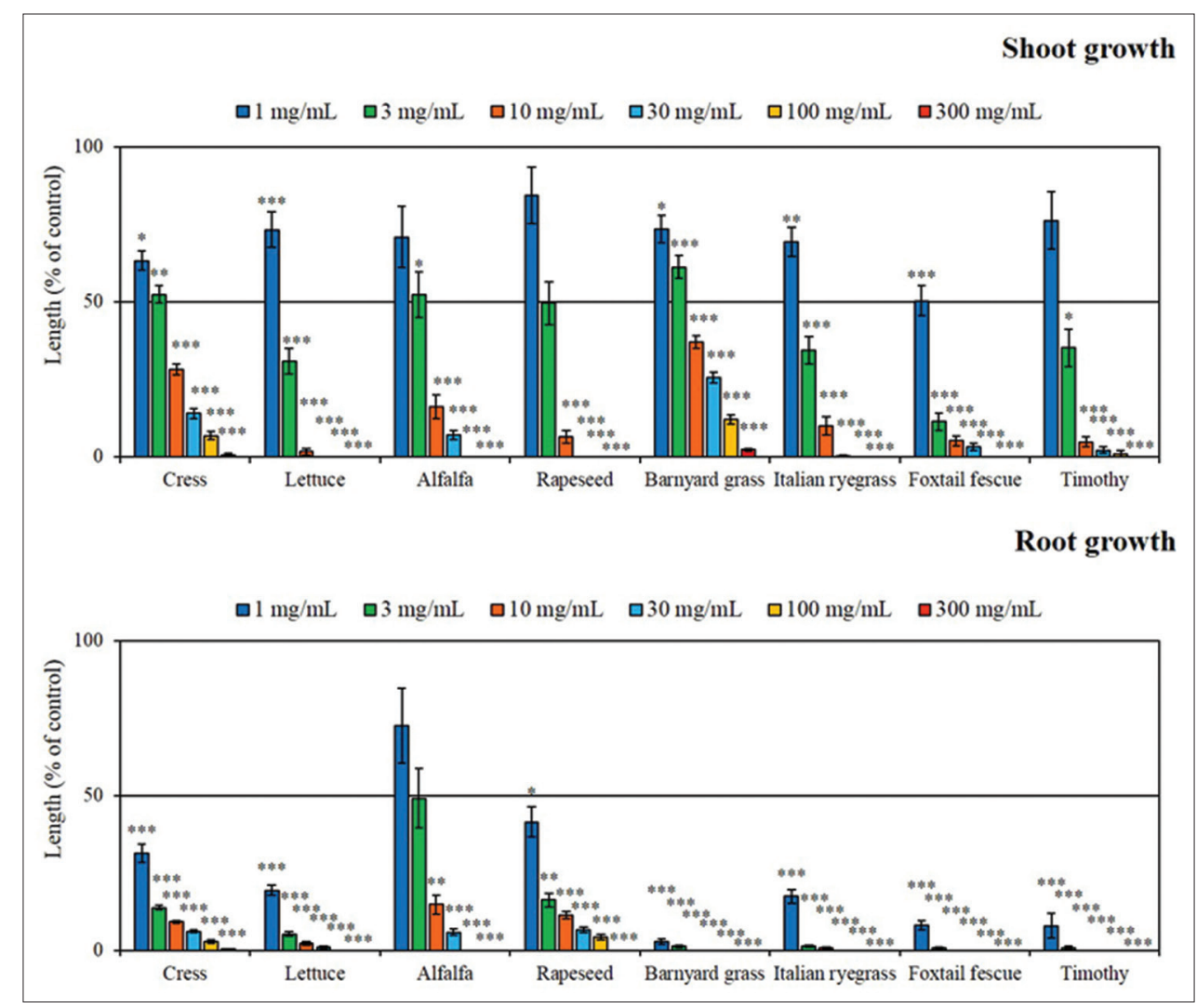

Fig 2. The growth inhibitory effects of Acacia concinna pod extracts on the shoot and root length of cress, lettuce, alfalfa, rapeseed, barnyard grass, Italian ryegrass, foxtail fescue and timothy. All test plants were treated with the concentrations corresponding to the extracts obtained from $1,3,10,30,100$ and $300 \mathrm{mg}$ dry weight equivalent extract $/ \mathrm{mL}(\mathrm{mg} / \mathrm{mL})$. Mean $\pm \mathrm{SE}$ from two independent experiments with three replications (10 seedlings/replication) for each experiment $(n=60)$ are shown. Significant differences between control and treatments are represented by asterisks: ${ }^{*} P<0.05,{ }^{* *} P<0.01,{ }^{* *} P<0.001$ (One-way ANOVA, Post hoc by Dunnett's test).

foxtail fescue and timothy seedlings were completely inhibited, and Italian ryegrass, lettuce, cress, rapeseed and alfalfa were significantly inhibited by $0.7,2.3,9.2,11.3$ and $14.8 \%$ of control length, respectively. The extract at $300 \mathrm{mg}$ dry weight equivalent extract/mL, the root of cress was significantly inhibited by $0.4 \%$ of control length, and the other test plants were completely inhibited. There was a negative correlation coefficient $(\mathrm{R})$ between pod extract concentration and root length percentage in all test plants (Table 1). The root length of cress, alfalfa and barnyard grass had a significant negative correlation with the pod extracts and giving the correlation coefficients of $-0.543,-0.521$ and -0.428 , respectively $(P<0.01)$. The $I_{50}$ value on the root length of all test plants ranged between 0.02 to $2.59 \mathrm{mg}$ dry weight equivalent extract $/ \mathrm{mL}$ (Table 2). Root growth of barnyard grass was the most susceptible to the extract, followed by cress, lettuce, foxtail fescue, timothy, Italian ryegrass, rapeseed and alfalfa.

\section{Isolation of an allelopathic substance from pod extracts of $\boldsymbol{A}$. concinna}

The pod extracts of $A$. concinna were purified as described in Fig. 1. The biological activity of the separated fractions through a silica gel column is shown in Fig. 3. Only fraction 6 (F6) showed significant inhibitory activity. Shoots and roots of cress were inhibited by 23.5 and $33.2 \%$ of control length, respectively. Fraction 6 was further purified by Sephadex LH-20 and reverse phase $\mathrm{C}_{18}$ cartridge, an active substance (ACP-1) was separated by reverse phase HPLC. The active substance was found at the retention time of 40-55 min. The residue was colorless. Shoots and roots of cress were inhibited by the substance at 27.1 and $14.4 \%$ of control length, respectively.

\section{DISCUSSION}

A. concinna pod extracts inhibited the shoot and root length of selected test plants with different growth inhibition percentages. The effectiveness of the extracts varied with their concentration and test plants. These results are supported by others studies which noted that the inhibitory activity depended on extract concentration (Parvez et al., 2004, Shunjie et al., 2008, Moosavi et al., 2011; Mousavi et al., 2013). Differences in the biochemical and physiological nature of test plants may be responsible for inhibitory effects of the extracts (Sodaeizadeh et al., 2009). 
Table 1: Correlation coefficient $(R)$ between the pod extract concentration and the growth of eight test plants

\begin{tabular}{lcc}
\hline Test plants & \multicolumn{2}{c}{ Correlation coefficient $(\mathbf{R})$} \\
\cline { 2 - 3 } & Shoot length & Root length \\
\hline Cress & $-0.669^{\star *}$ & $-0.543^{\star *}$ \\
Lettuce & $-0.358^{*}$ & $-0.383^{*}$ \\
Alfalfa & $-0.503^{\star *}$ & $-0.428^{\star *}$ \\
Rapeseed & $-0.447^{* *}$ & $-0.521^{\star *}$ \\
Barnyard grass & $-0.743^{\star *}$ & $-0.355^{*}$ \\
Italian ryegrass & $-0.461^{* *}$ & $-0.333^{*}$ \\
Foxtail fescue & -0.244 & -0.238 \\
Timothy & $-0.417^{*}$ & -0.212 \\
\hline
\end{tabular}

Correlation coefficient: R. Asterisks indicates statistical

significance: ${ }^{*} P<0.05$; ${ }^{* *} P<0.01$

Table 2: The concentrations required for $50 \%$ inhibition $\left(I_{50}\right.$ value) of aqueous methanol extracts of Acacia concinna pods on the shoot and root length of test plants

\begin{tabular}{lcc}
\hline Test plants & $\boldsymbol{I}_{50}$ (mg dry weight equivalent extract $\left./ \mathrm{mL}\right)$ \\
\cline { 2 - 3 } & Shoot length & Root length \\
\hline Cress & 2.70 & 0.29 \\
Lettuce & 1.82 & 0.31 \\
Alfalfa & 2.71 & 2.59 \\
Rapeseed & 2.84 & 0.58 \\
Barnyard grass & 5.17 & 0.02 \\
Italian ryegrass & 1.85 & 0.52 \\
Foxtail fescue & 1.00 & 0.33 \\
Timothy & 2.04 & 0.33 \\
\hline
\end{tabular}

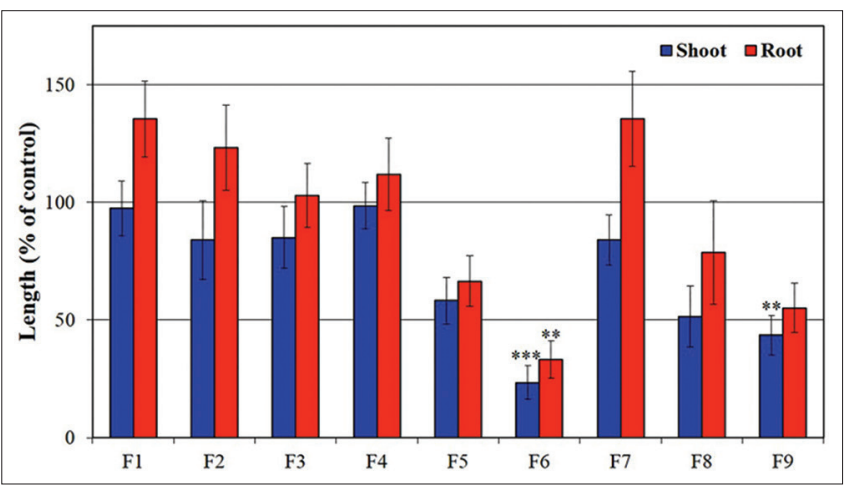

Fig 3. The effects of separated fraction through silica gel column on the growth of cress. The pod extract was used for the experiment in the concentration of $100 \mathrm{mg}$ dry weight equivalent extract $/ \mathrm{mL}$. Mean \pm SE from three replications with 10 seedlings/replication $(n=30)$ are shown. Significant differences between control and treatments are represented by asterisks: ${ }^{* *} P<0.01,{ }^{* * *} P<0.001$ (ANOVA, Post hoc by Dunnett's test).

The $I_{50}$ values of $A$. concinna pod extracts indicated that the extract had higher inhibitory effects on roots than their shoots. A similar result was reported by Arowosegbe and Afolayan (2012) that Aloe ferox extract had inhibition on the root growth of test plants more than on the shoot growth. This may be because the root is the first organ exposed to the extracts for absorbance of allelochemicals (Salam and Kato-Noguchi, 2010). In this study, all test plants were germinated and/or grown in a single Petri dish which contained only aqueous methanol extracts of A. concinna pods. During the initial growth of the plants, light is unnecessary and the plants use nutrients from their seeds and there was no intra-species competition for nutrients (Fuerst and Putnam, 1983). Therefore, the inhibitory activity on the growth of test plants resulted from the presence of allelochemicals in the pod extracts rather than extraneous competition factors. Bioassay-directed fractionations of the extract resulted in the isolation of an allelopathic active substance ACP-1 with growth inhibitory activity. This research is the first report of the presence of allelopathic active substances in $A$. concinna pods.

\section{CONCLUSIONS}

A. concinna pod extracts showed the growth inhibitory effect on selected test plants. The allelopathic active substance ACP-1 was isolated from the pod extracts and is likely to be responsible for the inhibitory effects of the extracts. The pods and the extracts could, therefore, be utilized as a weed management options in sustainable agriculture. Further research under the field condition is necessary to substantiate these results.

\section{ACKNOWLEDGEMENTS}

The authors would like to express our sincere gratitude to the Government of Japan for supporting the scholarship for Sutjaritpan Boonmee.

\section{Authors' contributions}

Sutjaritpan Boonmee: Extraction and isolation of substance, bioassay, measurements and analysis the data and wrote the manuscript. Hisashi Kato-Noguchi: Experimental design, supervise data analysis and made discussion.

\section{REFERENCES}

Aktar, W., D. Sengupta and A. Chowdhury. 2009. Impact of pesticides use in agriculture: Their benefits and hazards. Interdiscip. Toxicol. 2(1): 1-12.

Arowosegbe, S. and A. J. Afolayan. 2012. Assessment of allelopathic properties of Aloe ferox Mill. on turnip, beetroot and carrot. Biol. Res. 45: 363-368.

Chandra, S. and D. S. Rawat. 2015. Medicinal plants of the family Caryophyllaceae: A review of ethno-medicinal uses and pharmacological properties. Integr. Med. Res. 4(3): 123-131.

Cheng, F. and Z. Cheng. 2015. Research progress on the use of plant allelopathy in agriculture and the physiological and ecological mechanisms of allelopathy. Front. Plant Sci. 6: 1-16.

Dahanukar, S. A., R. A. Kulkarni and N. N. Rege. 2000. Pharmacology of medicinal plants and natural products. Indian J. Pharmacol. 32: S81-S118. 
Duke, S. O., K. C. Vaughn, E. M. Croom and H. N. Elsholy. 1987. Artemisinin, a constituent of annual wormwood (Artemisia annua) is a selective phytotoxin. Weed Sci. 35: 499-505.

Fuerst, E. P. and A. R. Putnam. 1983. Separating the competitive and allelopathic components of interference: Theoretical principles. J. Chem. Ecol. 8: 937-944.

Fujii, Y., S. S. Parvez, M. M. Parvez, Y. Ohmae and O. lida. 2003. Screening of 239 medicinal plant species for allelopathic activity using the sandwich method. Weed Biol. Manag. 3: 233-241.

Gafur, M. A., T. Obata, F. Kiuchi and Y. Tsuda. 1997. Acacia concinna saponins. I. Structures of prosapogenols, concinnosides A-F, isolated from the alkaline hydrolysate of the highly polar saponin fraction. Chem. Pharm. Bull. 45(4): 620-625.

Gandhi, R. and S. M. Snedeker. 1999. Consumer concerns about pesticides in food. Fact Sheet No. 24. Cornell University Program on Breast Cancer and Environmental Risk Factors (BCERF), Cornell University, Ithaca, New York, p. 6.

Kapoor, L. D., A. Singh, S. L. Kapoor and S. N. Srivastava. 1969. Survey of India plants for saponins, alkaloids and flavonoids. I. Lloydia. 32(3): 297-304.

Kukhetpitakwong, R., H. Chariya, H. Preecha, L. Vichai, S. Jarunee and K. Watcharee. 2006. Immunological adjuvant activities of saponin extracts from the pods of Acacia concinna. Int. Immunopharmacol. 6: 1729-1735.

Moosavi, A., T. A. Reza, A. Abouzar and G. M. Hossain. 2011. Allelopathic effects of aqueous extract of leaf stem and root of Sorghum bicolor on seed germination and seedling growth of Vigna radiata L. Notulae Sci. Biol. 3(2): 114-118.

Mousavi, S. H., K. H. Alami-Saeid and A. Moshatati. 2013. Effect of leaf, stem and root extract of alfalfa (Melilotus indicus) on seed germination and seedling growth of wheat (Triticum aestivum). Int. J. Agric. Crop Sci. 5(1): 44-49.

Nasrine, S., S. M. El-Darier and H. M. El-Taher. 2011. Allelopathic effect from some medicinal plants and their potential uses as control of weed. Int. Conf. Biol. Environ. Chem. 24: 15-22.

Parvez, S. S., M. M. Parvez, Y. Fujii and H. Gemma. 2004. Differential allelopathic expression of bark and seed of Tamarindus indica $\mathrm{L}$.
Plant Growth Regul. 42: 245-252.

Raja, X. Y. and R. Sivaraj. 2012. Screening of secondary metabolites and antibacterial activity of Acacia concinna leaves. Int. Res. J. Pharm. 3(10): 130-131.

Rao, T. P., H. H. Htay, N. K. Yasuda, H. Sugino, Ohkubo, T. Hayashi, T. Okamoto and K. Suzuki. 2014. Antioxidant and anti-thrombotic properties of selected plant extracts of Asia. Austin J. Nutr. Metab. 1(1): 1-6.

Rawat, L. S., R. K. Maikhuri, V. S. Negi, Y. M. Bahuguna, D. S. Pharswan and A. Maletha. 2016. Allelopathic performance of medicinal plants on traditional oilseed and pulse crop of Central Himalaya, India. Natl. Acad. Sci. Lett. 39(3): 141-144.

Rice, E. L. 1984. Allelopathy, $2^{\text {nd }}$ ed. Academic Press, New York, p. 422.

Salam, M. A. and H. Kato-Noguchi. 2010. Evaluation of allelopathic potential of neem (Azadirachta indica. A. Juss) against seed germination and seedling growth of different test plant species. Int. J. Sustain. Agric. 2(2): 20-25.

Sharma, A., S. Vishnu, K. K. Tarun and S. Ruchi. 2014. A review on antidermatophytic efficiency of plant essential oils. Int. J. Pure Appl. Biosci. 2(6): 265-278.

Shunjie, Z., F. Ma, W. Yubo and S. Zhen. 2008. Study on allelopathy of soybean root exudates. J. Northeast Agric. Univ. 10: 83-91.

Sodaeizadeh, H., M. Rafieiolhossaini, J. Havlı'k and P. V. Damme. 2009. Allelopathic activity of different plant parts of Peganum harmala L. and identification of their growth inhibitors substances. Plant Growth Regul. 59: 227-236.

Soltys, D., U. Krasuska, R. Bogatek and A. Gniazdowska. 2013. Allelochemicals as bioherbicides-present and perspectives. In: Price, A. J. and J. A. Kelton (Eds.), Herbicides-Current Research and Case Studies in Use, InTech, Croatia, pp. 517-542.

Swain, T. 1997. Secondary compounds as protective agents. Ann. Rev. Plant Physiol. 28: 479-482.

Todkar, S. S., V. V. Chavan and A. S. Kulkarni. 2010. Screening of secondary metabolite and antibacterial activity of Acacia concinna. Res. J. Microbiol. 5(10): 974-979. 